\title{
El lenguaje de la violencia en el prólogo de la traducción latina del Corán impulsada por Pedro el Venerable*
}

\author{
José Martínez GázQuez
}

Universidad Autónoma de Barcelona

\begin{abstract}
RESUMEN
En este artículo se presenta un análisis del prólogo escrito por Robert de Ketton a la traducción latina del Corán, realizada por mandato de Pedro el Venerable, abad de Cluny, en el que se muestra la mentalidad y la actitud agresiva y de violencia que mantienen los cristianos ante el islam a través del vocabulario empleado por el traductor.

RÉSUMÉ

Dans cet article, on cherche à montrer comment le prologue écrit par Robert de Ketton à la traduction latine du Coran, réalisée sur l'ordre de Pierre le Vénérable, abbé de Cluny, fait apparaître la mentalité d'agressivité et de violence entretenue par les chrétiens face à l'islam au travers du vocabulaire employé par le traducteur.
\end{abstract}

La primera traducción latina del Corán fue la traducción impulsada y pagada a sus expensas por Pedro el Venerable ${ }^{1}$ y realizada en España en alguna ciudad de la ribera aragonesa del Ebro, probablemente en Tarazona, recién conquistada a los musulmanes, donde se encontraban los traductores que intervinieron en ella, especialmente Robert de Ketton, el cual en compañía de Hermann de Carintia estaba traduciendo textos de matemática y astronomía para el obispo Miquel, teniendo como princi-

* Este trabajo se ha elaborado en el marco del proyecto de investigación BFF2000-1097C02-02, financiado por la DGICYT.

1. Marie-Thérèse D’Alverny, «Deux traductions latines du Coran au Moyen Âge», Archives d'histoire doctrinale et littéraire du Moyen Agge, 16, 1948, p. 69-131; reed. in: Marie-Thérèse D'ALverny, La connaissance de l'Islam dans l'Occident médiéval, vol. I, Aldershot: Variorum, 1994. José Martínez Gázquez, «Trois traductions médiévales latines du Coran: Pierre le VénérableRobert de Ketton, Marc de Tolède et Jean de Segobia», Revue des études latines, 80, 2002, p. 223-236.

CEHM, $\mathrm{n}^{\circ} 28,2005$, p. 243-252 
pal interés de sus trabajos la búsqueda del Almagesto. Robert de Ketton pagado por el abad de Cluny, dedicó su tiempo entre 1142 y 1143 a la realización de esta primera traducción del Corán a la lengua latina. Pedro el Venerable, decidió esta empresa como parte de un proyecto de refutación del Islam, a partir de los impulsos que recibe ante la realidad que fue conociendo de forma directa en sus contactos en la Península con ocasión de su viaje en 1142 para visitar los nuevos monasterios cluniacenses que se estaban creando en la línea de frontera con los territorios musulmanes y en donde ve de cerca las interrelaciones de musulmanes y cristianos, separados por la tenue línea de una frontera territorial ${ }^{2}$.

Robert de Ketton, el traductor, escribe un prólogo con la dedicatoria a Pedro el Venerable en el que encontramos algunas indicaciones que explican los criterios que han guiado al Abad a hacer el encargo de la traducción y su realización al traductor. Su texto es el siguiente ${ }^{3}$ :

Prephatio Ruberti translatoris ad dompnum Petrum abbatem Cluniacensem in libro legis Sarracenorum quem Alchoran uocant, id est, collectionem preceptorum quam Mahumet pseudopropheta per angelum Gabrielem quasi de celo sibi missa confixit.

Domino suo Petro diuino instinctu Cluniacensi abbati, Robertus Kettonnsis suorum minimus in Deo perfecte gaudere ubi sepius atque sero percipi, qualiter quamtumue tuus animus solius et totius boni studiosus sitiuit sterilem paludem Sarracene secte, nondum uise fertilem efficere suumque puteum exaurire propugnaculaque prorsus diruere. Ego peditis tamen offitio praeuii functus uias et aditus diligentissime patefeci. Quis enim gressum dilatabit, quis non citissime curret, ut hostis errorem ipsumque uictum semetipsum autem tenere sententiam ubique firmam atque uictricem agnoscat? Latinitas tamen omnis hucusque non dicam pernitiosis incommodis ignorantie, negligentie pressa, suorum hostium causam et ignorare et non depellere passa est. Tua uero peruigil prouidentia sanctissimos et preelectos ecclesie doctores semper aspitiens hoc nullatenus noluit. Cum illum itaque patrem atque doctorem cuius omnis hereditas omni pro sua facultate uenalis statuitur tu discipulus atque filius imiteris nusquam alias reflexus speraui me licet omnium tuorum minimum tuam gratiam promereri posse si mundani sompni militieque uoto postposito tuis studiose nutibus inuigilarem. Unde quamquam te uelud alumpnum et heredem sapientie chohors sapientium circumflua constipet suas manus tuis nutibus benigne conferens quorum conuentu me minime dignum ad hec adhuc sentio. Vestrum tamen munusculum puteum presignatum

2. Pedro el Venerable deja constancia de estos hechos en diversas ocasiones. En su Epistola ad Bernardum Clareuallis para enviarle un ejemplar de la nueva traducción, «Mitto uobis carissime nouam translationem nostram contra pessimam nequam Mahumet heresim disputantem, quae dum nuper in Hispania morarer, meo studio de Arabica uersa est in Latinam», y en el amlio prólogo de su Liber contra sectam siue haeresim Saracenorum. Ver James Kritzeck, Peter the Venerable and Islam, Princeton, 1964, apéndices 3 y 6 respectivamente.

3. Ofrecemos el presente texto tomado de nuestra edición crítica en preparación del texto latino del Corán traducido por Robert de Ketton. 
pandens, saltim semel non oblique tuis tuus perspicax intuitus queso dignetur aspicere.

Quamquam enim me fragili fulcitum ingeniolo plura presserunt incommoda, tum hic eloqui penuria illinc scientie tenuitas, tum id quod ad nil agendum est eficatius socordie, uidelicet, negligentieque mater disperatio multiplex ob translationis nostre uilem et dissolubilem ac incompaginatam materiam pro sui modo prorsus, Arabico tantum semoto uelamine tue maiestati prebendam, non minus tamen obnixe tuum obsequium aggressus sum, confixus nil effectum quassari, quo tuum uotum igne diuino plenum aspirat. Lapides igitur et ligna ut tuum deinde pulcherimum et commodissimum hedifitium cementatum et indisolubile surgat, nil excerpens, nil sensibiliter nisi propter intelligentiam tantum alterans actuli Mahumetique sumum, ad ipsius tuis follibus extinctum et puteum ad illius exhaustum tuo uase ignisque nostri uestri tuo uentilabro fomentum atque feruorem nostrique fontis eductu tuo discursum patefeci.

Ius igitur exigit ut hostium castrum imo caueam delendo, puteum exsiccando, cum tu sis dextre mundi pars optima, cos religionis accutissima, caritatis manus largiflua tuorum munimen corrobores, tella diligenter accuas fontemque suum fortius emanare sueque caritatis uallum protensius atque capatius effitias. Si quis me uilitatis et incompositionis rerum atque uerborum arguat, licet iuste forsan, obsecro tamen ut cesset, sciens meum numquam hoc fuisse propositum, floribus uenenum tegere, remque uilem et abiciendam deaurare, quod et animi tui lux admirabilis mira facundia polens manu fortissima iungens, mihi inde sepius et studiose deliberanti summatimque dicere uolenti clarificauit. Lex tamen ista licet letifera multis in locis maximum testimonium argumentumque firmissimum sanctitatis et excellentie uestre legis uidentibus et electis prebet. Istud quidem tuam minime latuit sapientiam, que me compulit interim astronomie geometrieque studium meum principale pretermictere.

Sed ne prohemium fastidium generet ipsi finem impono. Terque celesti celum omne penetranti, celeste munus uoueo quod integritatem in se scientie complectitur, que secundum numerum et proportionem atque mensuram celestes circulos omnes et eorum quantitates ac ordines et habitudines, demum stellarum motus omnimodos et earumdem effectus atque naturas et huiusmodi cetera dilligentissime dilligentibus aperit. Nunc probabilibus non nunquam neccessariis argumentis innitens. Explicit prologus.

Al final de la traducción del Corán encontramos en algunos manuscritos $^{4}$ un colofón en el que se ratifica que la traducción del Corán que los precede la mandó traducir el Abad de Cluny, Pedro el Venerable, el año

4. Aunque no se encuentra esta parte del colofón en el ms. Arsenal 1162, si que aparece en otros como los mss. 4071 y 4072 de la Biblioteca Apostólica Vaticana. Véase Marie Thérèse D’Alverny, «Deux traductions latines du Coran...», p. 131; id., «Quelques manuscrits de la "Collectio Toletana"», in: G. Constable et J. Kritzeck (ed.), Petrus Venerabilis. 1156-1956, Roma (Studia Anselmiana, 40), 1956, p. 202-218; reed. in: Marie-Thérèse D’Alverny, La connaissance de l'Islam dans l'Occident médiéval, vol. IV, Aldershot: Variorum, 1994; Henri Lamarque, «En marge du Coran latin», Mélanges foan Soubiran Pallas, 59, 2002, p. 339-355. 
1143, año de la conquista de Coria por el Alfonso VII, coronado emperador de Castilla y León. Dice como sigue:

Explicit liber legis dyabolice Saracenorum, qui Arabice dicitur Alchoran, id est, collectio capitulorum siue preceptorum.

Hunc librum fecit dominus Petrus Cluniacensis Abbas transferri [fol. 127v ${ }^{\circ}$ ] de arabico in latinum a Petro magistro Toletano iuuante Petro monacho scriptore, cum esset idem dominus ac uenerabilis abbas in Hispaniis constitutus cum glorioso imperatore Adefonse eo anno quo idem gloriosus imperator Choriam ciuitatem cepit et Sarracenos inde figauit.

La Crónica Adefonsi imperatoris ${ }^{5}$, de autor anónimo, pero probablemente contemporáneo de los hechos acaecidos, narra la reconquista y entrega al emperador de la ciudad de Coria, mencionada como referencia en el colofón de la traducción del Corán, de la manera siguiente:

II 36, Postquam autem reddita est ciuitas imperatori, mundata est ab inmumditia barbarice gentis et a contaminatione Mahometis et, destructa omni spurcitia paganorum ciuitatis illius et templi sui, dedicauerunt ecclesiam in honore sancte Marie semper uirginis et omnium sanctorum et ordinauerunt ibi episcopum uirum religiosum nomine Nauarronem, sicuti antiquitus fuerat sedes episcopalis tempore Ildefonsi archiepiscopi et Recaredi regis, quando tota illa terra Christianorum erat a Mediterraneo usque ad mare Oceanum. Capta est autem ciuitas Cauria in era CLXXX $[\Pi$ post millesimam et in mense iunio.

Apenas seis años antes en una campaña de hostigamiento de las tropas del emperador por tierras de Jaén se dice,

II 26, Et multe cohortes predatorie ambulauerunt per dies multos a longe et predauerunt totam terram de Iaen et Baeçe et Ubete et Anduger et multarum aliarum ciuitatum et miserunt ignem in omnibus uillis, quascunque inueniebant, et synagogas eorum destruxerunt et libros legis Mahometi combuserunt igne. Omnes uiri doctores legis, quicunque inuenti sunt, gladio trucidati sunt. Voneas et oliueta et ficulneas et omnes arbores fecerunt incidi et omnis locus, quemcunque pedes eorum calcauerunt, uastatus remansit.

Llama la atención que entre las múltiples atrocidades que se relatan, cometidas en la conquista de Coria, semejantes a las vividas por otras muchas ciudades, se subraya que se ha limpiado la ciudad de la inmundicia y la contaminación de Mahoma y su doctrina y se han destruido sus mezquitas, y además en la campaña de Jaén, coincidiendo en todo lo sus-

5. Citamos los textos por la Chronica Adefonsi imperatoris, Antonio Maya Sánchez (ed.), in: Chronica Hispana saeculi XII, E. Falque, J. Gil y A. Maya (dir.), Turnholt: Brepols (Corpus Christianorum. Continuatio medievalis, LXXI), 1990 y Maurilio Pérez González, Crónica del emperador Alfonso VII, introducción, traducción, notas e índices, León: Prensas de la Universidad, 1997. Véase una valoración detallada y documentada con las últimas referencias bibliográficas de la Crónica en Daniel Baloup, «Reconquête et croisade dans la Chronica Adefonsi imperatoris (ca 1150)», Cahiers de linguistique et de civilisation hispaniques médiévales, 25, 2002, p. 453-480. 
tancial, que se resume en que «todo lugar que hollaron sus pies quedó devastado» ${ }^{6}$, se añade que se echó al fuego la Lex Mahometi y se dio muerte a los sabios de la ley coránica allí donde se les encontró.

Asesinar a los ministros religiosos musulmanes, destruir las mezquitas y quemar el Corán, sin duda, son acciones opuestas a la declarada actitud de Pedro el Venerable, que en el mismo tiempo en que esto ocurre está impulsando la traducción del conjunto de textos con los que tiene la intención de conseguir una más clara percepción del islam y de Mahoma para llevar a cabo una refutación intelectual de las doctrinas del islam, y conseguir su conversión, según declara en su obra Contra sectam siue haeresim Sarracenorum, de forma pacífica ${ }^{7}$. Pero quizá no son tan diferentes, impregnadas todas por el ambiente en que se producen, y sólo son manifestaciones diversas de una misma actitud de mayor o menor agresividad hacia los musulmanes y su religión el islam.

Los diversos detalles que encontramos en este colofón concuerdan con las noticias de estos mismos acontecimientos mencionadas en la crónica del reinado del rey Alfonso VII. Ofrece los datos de la traducción, impulsada por Pedro el Venerable y realizada por Robert de Ketton y añade, además, la relación del Abad con el emperador Alfonso, al que los cluniacenses estaban ayudando en la Reconquista, e implantándose en la Península de resultas de esta política, y por ultimo la conquista de Coria y la puesta en fuga de los sarracenos que en ella vivían. Podríamos pensar que esta puesta en fuga fue bastante más que eso, si atendemos a lo que se narra en la crónica con la indicación de las acciones que subrayan que la ciudad fue limpiada de la inmundicia de aquella gente bárbara y de la contaminación de Mohoma, «mundata est ab inmunditia barbarice gentis et a contaminatione Mahometis», y en una referencia más específica a los aspectos religiosos se hace mención de la destrucción de sus mezquitas, «et destructa omni spurcitia paganorum ciuitatis illius et templi sui». No podemos creer que se trata de términos tomados al azar por el cronista. Sin duda que se trata de una designación de las personas y los hechos, ante los que se tiene ya una determinada actitud y que las palabras mismas delatan. Términos como inmunditia, contaminatione, spurcitia... son designaciones claras de la privación de dignidad que se hace a aquellas gentes que se ha vencido y expulsado, y barbarice gentis o paganorum transparentan unas formas de jerarquización en las que a los musulma-

6. M. Pérez González, Crónica del emperador..., p. 106.

7. Se ha prodigado siempre el análisis de la formulación que Pedro el Venerable dio a esta idea como "Aggredior inquam uos, non ut nostri sepe faciunt armis sed uerbis, non ui sed ratione, non odio sed amore». Ver James Kritzeck, Peter the Venerable and Islam, Princeton, 1964, Liber contra Sectam, p. 231. 
nes se les coloca en el ínfimo escalón entre los pueblos con los que se han de enfrentar los cristianos.

Nos parece que puede ayudarnos a captar mejor este punto de vista el análisis del contenido del prólogo del traductor Roberto de Ketton. En él, como es habitual en el género de los prólogos, donde acostumbran los traductores a ofrecer los criterios que han orientado su esfuerzo, se nos dan los puntos de vista y las actitudes con las que ha realizado la obra que nos presenta. Las indicaciones que ofrece, nos permiten conocer su estado de ánimo, su propia conciencia de los motivos y el contexto en el que vive en el momento en que desarrolla su traducción.

De su lectura global, a pesar de tratarse de la traducción de un texto religioso, se tiene la sensación de que más bien nos están presentando un tratado o un relato de guerra o una campaña agresiva y denigratoria. Todo el lenguaje empleado tiene siempre una pluralidad de sentidos que denotan un simbolismo de los aspectos que conforman la visión de la realidad de estos hombres del mundo cristiano del siglo xII. El vocabulario en el que se expresa es rico y está lleno de metáforas y comparaciones que ayudan a llevar al ánimo del lector la necesidad de luchar contra tales doctrinas y sus impulsores. No es de admirar por eso que los lectores posteriores de esta traducción, por ejemplo, Juan de Segobia ${ }^{8}$ que hará una nueva traducción en 1456 para suplir sus defectos o posteriormente Maracci, acusen a Robert de Ketton de aparecer más como un rétor, que recoge metáforas de muchos campos de la actividad humana que van bien con la guerra y la violencia, y como un predicador que arenga desde el púlpito, que como un traductor fiel.

A lo largo del prólogo va empleando un vocabulario con valores metafóricos claramente militaristas y propiamente guerreros con el que presenta el propósito de Pedro el Venerable, al mandar traducir el Corán, y la finalidad de su mismo trabajo, como una acción más en un plan preconcebido como una lucha para derrotar a un enemigo que se encuentra en su fortaleza, propugnacula (7), o al que hay que destruir su campamento militar, hostium castrum delendo (33), desecar sus fuentes de aprovisionamiento, puteum exsiccando (33), o desenmascarar su error, hostis errorem (9) y, por el contrario, como buenos soldados peditis (8), concebir una estrategia vencedora uictricem (10), mantener los deseos militares, militieque uoto (17), afilar las armas, tela accuas (35), y construir una protección eficaz para defender a los soldados propios, uallum effitias (35).

8. Véase la edición del prólogo de esta traducción perdida en: José MARTínez GÁzQuEz, «El prólogo de Juan de Segobia al Corán (Qur'an) trilingüe (1456)», Mittellateinisches Fahrbuch, 38, 2003, p. 389-410; Darío Cabanelas Rodríguez, Juan de Segovia y el problema islámico, Madrid, 1952, p. 132 y ss.; Esteban LATOR, «Giovanni de Segovia e la prima versione bilingue del Corano», La civiltà cattolica, 96, 1945, p. 36-44. 
Encontramos claras expresiones llenas de agresividad y desprecio hacia el islam, al que se apostrofa con los peores epítetos: la charca estéril de la secta Sarracena, sterilem paludem Sarracene secte (6), un veneno que no se puede esconder entre flores, floribus uenenum detegere (38), un objeto vil y despreciable que no se ha de dorar, rem uilem et abiciendam deaurare (39), una doctrina mortal, lex letifera (41).

En el caso de Pedro el Venerable, Le Goff ha destacado su actitud más pacífica y tolerante y su interés, por primera vez expresado, de combatir a los musulmanes en el plano intelectual. En su tratado Liber contra sectam siue haeresim Sarracenorum escribe su deseo de relacionarse con los musulmanes

por la palabra, no por las armas, como hacen los nuestros con frecuencia, no por la fuerza, sino por la razón, no por el odio, sino por el amor ${ }^{9}$

y buscando conocer directamente en sus fuentes la doctrina y la obra de Mahoma, antes de proceder a su refutación ${ }^{10}$, no se esconde que pretende llevar adelante una verdadera lucha contra los musulmanes y el Islam. Una lucha que como buen monje sabe que ha de ser una lucha contra el Demonio y no dudará en encarnarla en Mahoma y sus seguidores. En esta lucha pone además un fin secundario, que ya había recomendado formar un christianum armarium ${ }^{11}$ para con él convertir a los musulmanes o al menos preservar la fe de los cristianos.

Examinando el contenido del prólogo en su totalidad, debemos distinguir dos aspectos principalmente: las indicaciones que se nos ofrecen de la actitud de Pedro el Venerable que es el que encarga el trabajo, lo patrocina y lo paga con generosidad y la actitud del traductor que, a pesar de declarar su empeño en mantener la objetividad, se identifica entusiasta con todas las indicaciones que se han señalado en el patrocinador de la traducción del Corán.

De manera general, pueden señalarse dos tipos de criterio en las observaciones que indica en su prólogo: las primeras, unas observaciones que se refieren indirectamente a la actitud de Pedro el Venerable y su propia opinión sobre el islamismo y la actitud general de la Cristiandad:

Un segundo orden de observaciones ante el texto que debe traducir directamente relacionadas con su modo de entender la traducción, con la forma material de verter el texto y el método seguido en ella. El conte-

9. Liber contra sectam siue haeresim Sarracenorum, cap. 25.

10. Jacques Le Goff, Los intelectuales en la Edad Media, Buenos Aires, 1965, p. 24-25.

11. «Quod si forte haec de qua agitur scriptura aut interpretes non habuerit, aut translata non profuerit, habebit saltem Christianum armarium etiam aduersus hos hostes arma quibus aut se muniat, aut quibus si forte ad certamen uentum fuerit, inimicos confodiat» (Liber contra sectam, p. 230). 
nido del prólogo, siguiendo su texto, nos presenta los siguientes conceptos en orden a sus criterios ante el islam y la traducción:

1. Dedicatoria a Pedro el Venerable

a) Su actitud

- agresividad del Abad ante la doctrina islámica, sediento por agotar al islam, qualiter quantumue sitiuit sum puteum exaurire (1. 6) y por derrotar sus defensas, propugnacula prorsus diruere (1. 7);

-mantenerse vigilante en todo momento: tua peruigil prouidentia (1. 12);

- organizar una actividad incesante y planes diversos de actuación y entre ellos:

*conocer el Islam para su refutación, ut hostis errorem ipsumque uictum semetipsum autem tenere sententiam ubique firmam atque uictricem agnoscat? (1. 9-10);

* seguir el impulso divino, tuum uotum igne diuino plenum aspirat (1. 27);

*construir el edificio de la refutación del islam con una argumentación sólida e indisoluble: Lapides igitur et ligna ut tuum deinde pulcherrimum et commodissimum edificium cementatum coagmentatum et indissolubile surgat (1. 28-29);

* establecer una opinión cristiana firme y victoriosa: tenere sententiam ubique firmam atque uictricem (1. 10).

b) Actitud de la Cristiandad

-ha mantenido durante siglos una ignorancia que acarrea los peores inconvenientes, pernitiosis incommodis ignorantie (1. 11);

-se ha dejado llevar de la negligencia: negligentie pressa (1. 11);

-ha ignorado el grave problema del islam sin actuar en consecuencia, suorum hostium causam et ignorare et non depellere passa est (1. 12).

c) La concepción del islam

Sus propios prejuicios condicionan su visión del islam como una charca estéril: sterilem paludem (1. 6); un veneno, uenenum (1. 38), algo despreciable y vil: remque uilem et abiciendam deaurare (1. 39).

d) Actitud necesaria exigida por el derecho mismo

La defensa de los cristianos da el derecho al ataque del enemigo, al exterminio total de sus fuerzas: Ius igitur exigit ut hostium castrum imo caneam delendo (1. 33).

Consecuentemente debe el Abad:

- corroborar a los suyos: tuorum munimen corrobores (1. 35);

- protegerlos dentro de unas defensas más amplias y capaces: sueque caritatis uallum protensius atque capatius effitias (1. 36);

- preparar las armas más aptas y afiladas: tela diligenter accuas (1. 35). 
2. Actitud del traductor

a) Ante el encargo de Pedro el Venerable:

-Adhesión incondicional al proyecto del abad: diligentissime patefeci (1. 8), gressum dilatabit (1. 9), citissime curret (1. 9);

-Tópico de la humilitas: suorum minimus (1. 5), omnium tuorum minimus (1. 16), me minime dignum (1. 19), fragili fulcitum ingeniolo (1. 22);

-Captación de benevolencia: si quis me uilitatis et incompositionis rerum atque uerborum arguat, licet iuste forsan, obsecro tamen ut cesset (1. 36-38);

-Acepta los puntos de vista del Abad: ut hostis errorem... agnoscat (1. 9$10)$;

-Colaboración total: tuum obsequium aggressus sum, lapides igitur et ligna... actuli Mahumetique sumum... patefeci (1. 30-32);

-Aceptando incomodidades: plura presserunt incommoda (1. 22);

-Olvido de sus intereses: me compulit interim astronomie geometrieque studium meum principale pretermictere (1. 43-44);

-Resultado de su trabajo: ob translationis nostre uilem et dissolubilem ac incompaginatam materiam (1. 24-25).

b) Ante la traducción

-Condiciones personales: fragili fulcitum ingeniolo (1. 22), eloqui penuriam illinc scientie tenuitas (1. 23), uilitatis et incompositionis rerum atque uerborum (1. 36-37);

-Método de traducción:

*al verter el texto coránico declara estar interesado sobre todo en apartar el velo de la lengua, Arabico tantum semoto uelamine tue maiestati prebendam, non minus tamen obnixe tuum obsequium aggressus sum, confixus nil effectum quassari, quo tuum uotum igne dinino plenum aspirat (1. 2527);

*no quiere abreviar ni alterar nada salvo para su comprensión: nil excerpens, nil sensibiliter nisi propter intelligentiam tantum alterans (1. 29-30);

*nunca ha tenido el propósito de falsear la percepción del islam: numquam hoc fuisse propositum (1. 38);

*no ha querido ocultar el veneno con flores: floribus uenenum detegere (1. 38);

*no ha pretendido dorar un objeto vil y despreciable: remque uilem et abiciendam deaurare (1. 39).

c) Ante Dios

Pedirle ayuda para encontrar el apoyo de los argumentos necesarios: celeste munus uoueo... necessariis argumentis innitens (1. 46).

Los textos que hemos considerado son diferentes desde varios aspectos, pertenecen a un género distinto, no tienen la misma finalidad, su 
estilo responde a intereses diversos, y, sin embargo, su comparación nos muestra que comparten una atmósfera, una comprensión de la realidad del islam que les une de manera significativa y lleva a sus protagonistas a enfrentarse a esa realidad de una misma forma agresiva y batalladora, con unos prejuicios que les impiden valorar en sus justos términos a su adversario y, a la vez, no les permiten comprender el conjunto de los detalles de su doctrina y su vida, presentándole con unos términos, con un vocabulario, que muestra principalmente una inmensa carga de agresividad y violencia. Nos muestra que tiene conciencia clara de participar en un proyecto que tiene como objetivo una lucha, en la que unos hacen uso de las armas, y otros, es su situación, hacen uso de la palabra.

En definitiva, los textos translucen un comportamiento, unas actitudes y un modo de pensar y actuar que se enmarcan en un ambiente de violencia física y moral al que no logran sustraerse ni siquiera espíritus tan cultivados y bien intencionados como podría ser el abad de Cluny, Pedro el Venerable, dotado de un talante más conciliador y pacífico que la gran mayoría de los hombres de su tiempo, inmersos en la predicación, organización o participación de las sucesivas cruzadas guerreras contra el Islam tanto en Oriente como en el Occidente peninsular.

El enemigo es pagano, es enviado de Satanás, y en nombre de la suma bondad del cristianismo, por una paradoja increíble, se propugnan una serie de acciones, sean de ámbito intelectual y moral o de ámbito guerrero, que tiene como finalidad el aniquilamiento total del enemigo. 